\title{
EZH2, An On-Off Valve in Signal Network of Tumor Cells
}

\author{
Shanshan Sun ${ }^{1}$, Feng Yu ${ }^{2}$, Lun Zhang ${ }^{1}$, Xuan Zhou ${ }^{1}$
}

1. The Maxillary Facial and Otorhinolaryngology Head \& Neck Surgery, Tianjin Medical University Cancer Institute \& Hospital, National Clinical Research Center for Cancer, Tianjin Key Laboratory of Cancer Prevention and Therapy, Huanhuxi Road, Tiyuanbei, Hexi District, TJ, China, 300060.

2. Department of tumor cell biology, Key Laboratory of Cancer Prevention \& Therapy of Tianjin; Tianjin Medical University Cancer Institute \& Hospital, National Clinical Research Center for Cancer, Huanhu West Road, Hexi District, Tianjin, PR China, 300060

Correspondence to: Dr. Xuan Zhou (Email: byron2000zhou@163.com)

Dr. Lun Zhang (Email: lunzhangchina@163.com)

\section{Key words:}

EZH2, Double facet, Signaling, Histone Modulation, Tumor

\begin{abstract}
Enhancer Zeste 2 (EZH2) is a histone methyltransferase catalyzing histone $\mathrm{H} 3 \mathrm{~K} 27 \mathrm{me} 3$ to mediate gene silence. It is implicated in governing various biological behaviors of human malignancies. In this review, we over-review EZH2 serves as an "ON-OFF VALVE"---not only as a critical epigenetic repressor, but as a brand-new activator for specific downstream targets as well. Time and space it "SWITCHING ON-OFF" depends on the context and its cellular type. Moreover, EZH2 could act as a Tumor-Defender under certain circumstances. Moreover, the "Mutual-Inhibition" relationship between EZH2 and microRNAs is elaborated. In addition, we focus on different functions of phosphorylatied EZH2 in tumor cells. Finally, EZH2 inhibitors are summarized and newly-discovered strategies of targeting-EZH2 treatment are prospected.
\end{abstract}

\section{Introduction}

Nowadays, histone methylation focused on epigenetic modifications widely regulates genomic biological processes, including gene expression, activity and function. The methytransferase EZH2 catalyzes histone $\mathrm{H} 3$ lysine 27methylation to form $\mathrm{H} 3 \mathrm{~K} 27 \mathrm{me}$. The polycomb repressor complex2 (PRC2) comprises three core subunits EZH2, EED, and $\mathrm{SUZ}_{2}{ }^{1}$. EZH2 interacts within $\mathrm{PRC} 2 / 3$ context with DNA methyltransferases (DNMTs) and serves as a recruitment platform for DNMTs ${ }^{2}$. H3K27me3 acts as repressive marks in promoter-targeted transcriptional silence. EZH2 is essential for lncRNAs-conducted gene-silence, which is exerted by interaction with histone repressive proteins Polycomb group $(\mathrm{PcG})$ family and recruitment them to gene loci ${ }^{3}$. There are two opposing groups of histone modifying complexes, the trithorax group (TrxG) of H3K4 histone methyltransferase (HMTase) and the PcG H3K27 HMTase, maintaining open and closed chromatin domains in HOX loci, respectively ${ }^{4}$. ncRNAs transcription in cis might enhance accessibility of TrxG proteins while PRC2 recruitment might be programmed by ncRNAs produced in trans, resulting in $\mathrm{H} 3 \mathrm{~K} 4$ or $\mathrm{H} 3 \mathrm{~K} 27$ methylation and transcriptional activation or silence ${ }^{3}$. Dysregulation of EZH2 PcG body formation thus depression its tumor-related genes promotes tumor progression ${ }^{5}$.

EZH2 is aberrantly and frequently overexpressed in various tumors ${ }^{6-13}$. Along with PRC2/EED-EZH2 epigenetic silencing complex, EZH2 is related to aggressive phenotype (high proliferation rate, triple-negative) of breast cancers ${ }^{9}$, lymph node metastasis ${ }^{14}$, glioblastoma(GBM) cancer stem cell (CSC) maintenance, self-renewal and tumor-initiating ${ }^{15}$. EZH2 exists in complex and atypical hyperplasia ${ }^{16}$, and early pathogenesis of squamous cell carcinoma (SCC). High EZH2 expression influences the cell sensitivity 
to cisplatin ${ }^{17}$ or tamoxifen ${ }^{10}$.

\section{Context-specific Dependent Transcriptional Activation or Repression}

\subsection{Epigenetically Switch Off----Mediating Tumor-related Gene Silence}

\section{Jack-of-All-Trades:}

\subsubsection{An Epigenetic Gatekeeper}

Due to the canonical function of EZH2 as an epigenetic silencer, the biology responses depend on its interaction with some functional molecules and its downstream targets, which are summed up into the following aspects.

\section{EZH2 Promotes Cancer Progression}

EZH2 is implicated in Epithelial-Mesenchymal Transition (EMT) process. Mechanistically, it epigenetically suppresses the epithelial marker---E-cadherin via $\mathrm{H} 3 \mathrm{~K} 27 \mathrm{me} 3$ modification of its promoter ${ }^{18}$, ${ }^{19}$, which is facilitated by MER/ERK activation ${ }^{20}$. Otherwise, EZH2 interacted with HDAC1/HDAC2 and Snail to form a multi-molecular complex contributing to E-cadherin silence ${ }^{21}$. EZH2 is required for Snail-Ring1 A/B recruitment to E-cadherin promoter locus. EZH2 and Ring1B form distinct complexes with Snail $^{22}$. As a result, E-cadherin inhibition is associated with advanced stage and poor clinical outcome.

MEK-ERK1/2-Elk-1 regulates EZH2 in association with breast cancer aggressivenes ${ }^{23}$. Elk-1 is an important molecule downstream from ERK for EZH2, leading to chromatin remodeling at certain foci, such as E-cadherin and RUNX3 ${ }^{24,25}$. Emerging evidences reveal RB-E2F3-EZH2 as a key oncogenic axis in cancer development and aggressiveness ${ }^{26,27}$. EZH2 affects bladder cancer progression in recurrence, which is primarily facilitated by $\mathrm{E} 2 \mathrm{~F} 3 \mathrm{a}^{28}$.

Conversely, EZH2 epigenetically silences the mesenchymal markers (TWIST and SLUG) in company with SUZ12 and HDAC2. The circadian clock gene Period2 (PER2), which serves as a transcriptional co-repressor, recruits them to binding sites of EMT genes (TWIST and SLUG) promoters to inhibit them. However, hypoxia induces PER2 degradation and suppression thus the co-repressors are dissociated, resulting in reactivation of the EMT genes ${ }^{29}$. Another mesenchymal marker, Integrin alpha2 (ITG $\alpha 2$ ), is repressed by EZH2 after ERK/AKT activation in colon cancer ${ }^{30}$.

\section{EZH2 Determines Cell Fate}

Several growth-suppressive genes (such as p21, p16, p27) and pro-death genes (such as FBOX32) are EZH2 downstream targets ${ }^{31,32}$. Therefore, EZH2 participates in proliferation, cell cycle arrest, senescence and apoptosis of tumor cells, particularly TP53 related. Targeting EZH2 leads to growth inhibition only in TP53 wild-type cells but not in TP53 mutant-type cells. Combination of EZH2 inhibitor with a Mutant p53 Re-activator can restore the sensitivity of TP53 mutant-type cells to DZNep ${ }^{33}$. Gastric cancer proliferation is altered after EZH2 downregulated, p53 upregulated by TET1 ${ }^{34}$. Cell proliferative arrest caused by doxorubicin is promoted by EZH 2 depletion in p53-mutant rather than in p53 wild-type cells ${ }^{35}$. In both p53 wild-type and p53-deficient cancer cells, EZH2 depletion abrogates both cell cycle G1 and G2/M checkpoints thus promotes DNA-damage induced apoptosis in response to genotoxic stress. In p53 wild-type cells, EZH2 modulates DNA damage response mainly through transcriptional repressing its direct target FBXO32, which interacts with $\mathrm{p} 21$ to induce its degradation. Whereas, EZH2 regulates p53-deficient cells through Chk1 activation without any relationship with FBXO32 $2^{36}$. Additionally, Interferon $\gamma$ Receptor 1 (IFNGR1) is a target directly silenced by EZH2 in MYC-driven prostate cancer cells. EZH2-mediated

inactivation of IFN- $\gamma$-JAK-STAT1 signaling confers proliferation and survival advantages ${ }^{37}$. EZH2 signals through CDK-pRb-E2F pathway to regulate cell cycle. In this regard, an EZH2-mediated signal loop, 
EZH2-CDK4/6-pRb-E2F1 induces GBM proliferation and cell cycle ${ }^{38}$. EZH2 is required for rapid growth in $\mathrm{SCLC}$, in which the E2F/Rb deregulation prominently occurs. The E2F/Rb pathway is disrupted not only through loss or mutation of Rb but also through DNA copy number gains of E2F transcription factors, leading to EZH2 activation and aberrant methylation promotion ${ }^{39}$.

EZH2 is specifically downregulated in senescent cells. Activated p53 repressed EZH2 through inhibiting its promoter via $\mathrm{p} 21^{40}$. Likewise, EZH2 restrain promotes cellular senescence in gastric cancer cells by $\mathrm{p} 21$ and $\mathrm{p} 16^{41}$. Notably, EZH2 is modulated by NF-kB pathway, which is associated with cellular senescence (the canonical NF- $\mathrm{kB}$ pathway) and malignancies (the alternative one). As a direct NF-kB target gene, EZH2 is inhibited by loss of NF-kB2/RelB in an Rb/E2F manner ${ }^{42}$. In fibroblasts, EZH2 antagonizes a panel of p53 target related to senescence. Thus, it is persumed that the alternative NF- $\mathrm{KB}$ pathway promotes tumorigenesis probably through suppression of p53 dependent senescence ${ }^{43}$.

Early in 2003, it has been illustrated that EZH2 is downstream of the pRB-E2F pathway, essential for proliferation of tumors ${ }^{42}$. As an E2F1 target, EZH2 serves as a critical regulator of E2F1-dependent apoptosis by antagonizing pro-apoptosis target $\mathrm{Bim}^{44}$.

\section{EZH2 Regulates Angiogenesis in Inverse Manners}

The role of EZH2 in angiogenesis could be divided into two conditions.

Most publications reported that EZH2 could exhibit an angiogenic effect, for instance in clear cell renal cell carcinoma ${ }^{6}$, inflammatory breast cancer ${ }^{45}$, NPC and $\mathrm{GBM}^{46}$. EZH2 and VEGF are highly expressed and correlated with adverse clinicopathologic characteristics and poor outcome in renal cancer ${ }^{6}$. In NPC, EZH2 promotes angiogenesis by inhibition of MiR-1/Endothelin-1, an autocrine regulator of endothelial cells as neovascularization in a VEGF-dependent manner ${ }^{12}$.

Nonetheless, EZH2 represses angiogenesis under hypoxia and ischemia for the reason that EZH2 contains hypoxia response element (HRE) ${ }^{47}$. In endothelial cells, hypoxia increases EZH2 to regulatory regions of two pro-angiogenic genes (eNOS and BDNF) promoters and augments the abundance of $\mathrm{H} 3 \mathrm{~K} 27 \mathrm{me} 3$ at these locations ${ }^{48}$.

\subsubsection{A Novel Defender---EZH2 Antagonizes the Carcinogenesis Effect}

Intriguingly, EZH2 exhibits tumor-suppressive ability in a couple of tumors. Camille proposed that high frequency of spontaneous $\gamma \delta$ T-cell leukemia (T-ALL) occurs in EZH2 biallelic deletion mice. The tumor cells show little residual H3K27me3 marks compared with controls ${ }^{49}$. Meanwhile, EZH2 links pancreatic regenerative proliferation to oncogenic transformation. Loss of EZH2 impairs pancreatic regeneration and accelerates $\mathrm{KRas}{ }^{\mathrm{G} 12 \mathrm{D}}$-driven neoplasia. Therefore, EZH2 might play an opposite role, namely, restraining the oncogenic process in the exocrine pancreas ${ }^{50}$.

\subsection{Epigenetically-independent Switch On---Triggering Signal Cascading}

Apart from mediating transcriptional silence, the novel function of signaling activation of EZH2 has been uncovered recently. This non-canonic function is independent of histone methyltransferase activity to some extent in respective manners.

In Glioblastoma multiforme (GBMs), EZH2 facilitates STAT3 methylation and enhances its activity ${ }^{51}$. EZH2 promotes tumor growth independent of gain or loss of $\mathrm{H} 3 \mathrm{~K} 27 \mathrm{me} 3$ via the upsteam inducer Akt. EZH2 enhances STAT3 activation by trimethylating lysine 180 in STAT3 preferentially in glioma stem-like cells (GSCs). EZH2 along with PRC2, interacts with STAT3 specifically human neural progenitor cells and GSCs but not in differentiate isogenic progeny, nor in established glioma cell lines. Conversely, in bulk tumor cells the EZH2 with the unphosphorylated S21 trimethylates $\mathrm{H} 3 \mathrm{~K} 27^{52}$. 
In castration-resistant prostate cancer (CRPC) cells, phosphorylation of EZH2 at S21 induced by $\mathrm{PI} 3 \mathrm{~K} / \mathrm{AKT}$ switches its function from a Polycomb repressor to a transcriptional co-activator of androgen receptor (AR) or other molecules, potentially ${ }^{53}$. Strikingly, pS21 EZH2 level elevates more significantly in CRPC while H3K27me3 level decreases with prostate cancer progression. That strongly supports EZH2 oncogenic activity in CRPC is independent of its Polycomb repressive function ${ }^{53}$. In natural killer/T-cell lymphoma (NKTL) cells, EZH2 directly promotes cyclinD1 transcription by binding to its promoter. Therefore, EZH2 overexpression confers a growth advantage independently of histone methyltransferase activity $^{54}$.

Concomitantly, Maria uncovered a unique role of EZH2 in activating, rather than repressing, NOTCH1 signaling in TNBC cells. Instead of dependence on histone methyltransferase activity and its PRC2-binding partners, EZH2 positively regulates NOTCH1 transcriptional activity to expend the breast stem cell poor, resulting in acceleration of breast cancer initiation and growth ${ }^{55}$.

Additionally, the DNA repair gene---PCNA-associated factor (PAF) and EZH2 could induce $\mathrm{Wnt} / \beta$-catenin signaling hyper-activation. Upon activation, PAF facilitates interaction between $\beta$-catenin and EZH2 to form PAF-EZH2- $\beta$ catenin transcriptional complex, which enhance target gene transactivation, independently of EZH2's methylatransferase activity, to promote intestinal tumorigenesis ${ }^{56}$.

Intriguingly, as for target gene NF- $\mathrm{BB}$, EZH2 functions as a double-facet molecule in ER-positive/negative breast cancer, either as a transcriptional activator or repressor. In aggressive breast cancer cells, EZH2 positively regulates NF- $\mathrm{KB}$ target gene expression independently of histone methyltransferase activity. Mechanistically, EZH2 forms a ternary complex with RelA and RelB to modulate a subset of NF- $\mathrm{KB}$ target genes by interdependent promoter occupancy. On the other hand, in ER-positive luminal-like breast cancer cells, EZH2 negatively regulates NF- $\kappa \mathrm{B}$ target genes. ER recruits PRC2 complex to the promoter of NF- $\kappa B$ target genes, leading to epigenetic silence ${ }^{57}$.

\section{Silencing Confrontation: EZH2 versus MicroRNAs}

The relationship between EZH2 and miRNAs could be divided into two sides:

On one side, EZH2 is negatively regulated by several miRNAs, such as miR-101 ${ }^{58}$, miR- $^{26 b^{59}}{ }^{60}$, miR- $98^{61}$, miR-144 $4^{62}$, let- $7 b^{63}$, resulting in various responses in tumor cells. Mechanistically, miRNAs directly inhibit EZH2 by targeting its 3'UTR. Of most, the tumor suppressive microRNA---miR-101 are frequently reported. MiR-101 weakens EZH2 and proliferation/migration capability and re-sensitizes drug-resistant cancer cells to cisplatin ${ }^{64}$. MiR-98, MiR-144, let-7b, MiR-32and MiR-1297 are respectively evidenced to impair EZH2, responsible for malignant behaviors or cell fate in OCSC $^{61,65}$, bladder cancer ${ }^{62}$, astrocytoma $^{66}$, and hepatocellular carcinoma (HCC) ${ }^{67}$.

On the other side, some tumor-suppressive miRNAs are silenced by a repressive chromatin structure involving H3K27me3 and EZH2. After co-treatment with HDAC and EZH2 inhibitor, miR-1246, miR-302a and miR-4448 are upregulated while their onco-targets DYRK1A, CDK2/BMI-1 and Girdin are downregulated, resulting in apoptosis, cell cycle arrest and reduced migration, respectively ${ }^{68}$. MiR-340 suppresses several oncogenes including EZH2 in $\mathrm{GBM}^{69}$. Besides, EZH2 is recruited by MYC to miR-26a promoter and cooperatively represses miR-26a to alter aggressive B-cell lymphoma survival and clonogenicity abilities $^{70}$. Of interest, EZH2 negatively modulates miR-200c transcription to form an auto-regulatory loop named "EZH2-miR200c-E2F3" as a driving force for PCa development". Noteworthily, the repressive effect on miRNAs is achieved by several components including EZH2. In 
coordination with SOX4 and HDAC3, EZH2 forms a co-repressor complex binding to miR-31 promoter, repressing miR-31 through an epigenetic mark by $\mathrm{H} 3 \mathrm{~K} 27 \mathrm{me} 3$ and histone acetylation ${ }^{72}$.

\section{Phosphorylation of EZH2---Separate Sites, Separate Effects}

Early in 2005, Tai-Lung reported that Akt physically interacted with EZH2 and phosphorylated it at

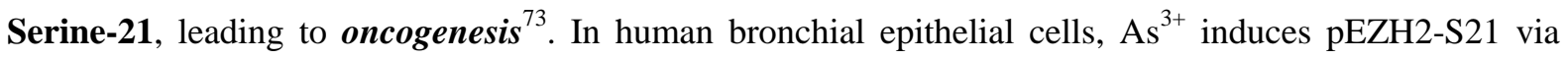
JNK/STAT3 and Akt. Activated pEZH2 leads to PRC2 dissociation from chromatin, thereby weaken $\mathrm{H} 3 \mathrm{~K} 27$ me3 in nuclei ${ }^{74}$. Strikingly, $\mathrm{H}_{2} \mathrm{O}_{2}$, the most important form of reactive oxygen species of cells in response to extracellular stress signals, induces EZH2 phosphorylation and activation of JNK, STAT3 and $\mathrm{Akt}^{75}$. As a result, several downstream genes are influenced by STAT3-induced EZH2 overexpression, such as the vitamin D receptor, resulting in cancer metastasis ${ }^{76}$. Notably, in HCC, Akt-mediated pEZH2-Ser21 is indispensable for an epigenetic auto-regulatory loop, in which cell cycle-related kinase (CCRK) induces EZH2 phosphorylation, thereby promoting pEZH2-S21-AR physical interaction for CCRK promoter co-occupancy and transcriptional activation ${ }^{77}$.

However, other researchers argued that Ser-21 was not a major phosphorylation site ${ }^{78}$. They believed that EZH2 phosphorylation was cell cycle-regulated ${ }^{79}$. The cyclin-dependent kinase, CDK1, phosphorylates EZH2 at threonine-345 and -487, which are essential for cell proliferation, embryonic stem cell self-renewal and lineage specification ${ }^{78,80}$. CDK1-EZH2 pathway is significant not only in cell cycle, but also in cancer cell migration and invasion. pEZH2-T487 disrupts EZH2 binding with other PRC2 components SUZ12 and EED, and thereby inhibits EZH2 methyltransferase activity, impairing cancer cell invasion ability ${ }^{81}$.

pEZH2-T345 is important for binding to ncRNA HOTAIR and the 5' end of Xist ${ }^{79}$. CDK1 and CDK2 phosphorylate EZH2 at Thr-350, which is vital for EZH2 recruitment and H3K27me3 levels maintenance at EZH2-target loci, thus mediates cell proliferation and migration ${ }^{82}$. Meanwhile, CDK2 also phosphorylates EZH2 at Thr-416 to contribute to TNBC malignancies ${ }^{83}$.

\section{Targeting-EZH2 Treatment}

Currently, a diverse of EZH2 inhibitors have been identified. Among these, 3-deazaneplanocin A (DZNep) is the most widely known to deplete EZH2 expression through an indirect pathway ${ }^{84}$. The anti-tumor effect of DZNep is well elucidated in literatures. DZNep inhibits H3K27me3 activity to suppress proliferation $^{68}$, induce apoptosis and cell cycle arrest ${ }^{31,}{ }^{85-88}$. DZNep downregulates H3K9 HMTase-SETDB1 gene at transcription level and H3K27 HMTase-EZH2 at post-translational level in lung cancer $^{89}$. Aside from EZH2, DZNep also depletes SUZ12, EED, H3K27me3 and cyclinA, whereas increases $\mathrm{p} 27^{\mathrm{kip} 188}$. EZH2 inhibition in mixed lineage leukemia fusion leukemia is therapeutically effective by diminishing leukemia stem cells via p16 upregulation. DZNep not only suppresses proliferation but also reduces leukemia initiating cells frequency ${ }^{90}$.

Moreover, DZNep-based EZH2 disruption remarkably attenuates GBM CSC self-renewal and tumor-initiating capacity ${ }^{15}$. Combination treatment of DZNep and IFN- $\gamma$ completely causes tumor growth arrest $^{37}$. Co-treatment with DZNep and pan-histone deacetypase inhibitor (panobinostat) exerts superior anti-EZH2 effect, leading to p16, p21 and p27 induction more significantly ${ }^{31}$.

As the fact that EZH2 catalyzes H3K27 methylation via transfer of a methyl group from the cofactor S-(S'-adenosyl)-L-methionine (SAM) ${ }^{91}$, some highly potent, selective, SAM-competitive, and cell-active EZH2 inhibitors are recognized, as exemplified by GSK926 and GSK343. Unlike DZNep, they directly and selectively inhibit PRC2 enzymatic activity ${ }^{92}$. GSK343 serves a more potent anticancer agent than DZNep 
and enhances sorafenib sensitivity in $\mathrm{HCC}^{84}$. SAM-competitive EZH2 inhibitors (including GSK343 and UNC1999) can induce autophagy in cancer cells ${ }^{84}$.

In addition, another small molecule inhibitor EI1 selectively inhibits proliferation and causes cell cycle arrest, and apoptosis in diffused large B-cell lymphomas (DLBCL) cells with EZH2 mutation (Y641F)---one of the hot-spot mutations of EZH2 identified in DLBCL and follicular lymphomas ${ }^{93}$.

\section{Concluding Remarks}

Collectively, in view of EZH2 doublefacet properties in epigenetic repression and signaling activation, its interplay in signal network seems crucially significant in tumor cells. Apart from the traditional epigenetic field, the critical valve "SWITCH-ON" mechanism remains elusive. Therefore, each detail mechanism of context-specific activation should be further elucidated. From these above, it could be summarized that---Before we take measures to target EZH2, it is wise to identify the exact role of EZH2 in proper time and space, to polish eyes on the Polycomb-dependent/-independent downstream genes, to recognize whether it is a defender or a gatekeeper.

As some newly-developed inhibitors are emerging in recent years, we are looking forward to the effective, feasible and specific EZH2 inhibitors, which may provide a new avenue for development new strategies for treatment.

\section{Conflict of Interests:}

There is no conflict of interests declared in this review.

\section{Acknowledgements}

This work is supported by grants from the National Science Foundation of China (NSFC81572492) and National Clinical Reaserch Center for Cancer (NCRCC)

\section{Reference:}

1. Wu L, Murat P, Matak-Vinkovic D, Murrell A, Balasubramanian S. Binding interactions between long noncoding RNA HOTAIR and PRC2 proteins. Biochemistry 2013; 52:9519-27.

2. Vire E, Brenner C, Deplus R, Blanchon L, Fraga M, Didelot C, et al. The Polycomb group protein EZH2 directly controls DNA methylation. Nature 2006; 439:871-4.

3. Rinn JL, Kertesz M, Wang JK, Squazzo SL, Xu X, Brugmann SA, et al. Functional demarcation of active and silent chromatin domains in human HOX loci by noncoding RNAs. Cell 2007; 129:1311-23.

4. Ringrose L, Paro R. Polycomb/Trithorax response elements and epigenetic memory of cell identity. Development 2007; 134:223-32.

5. Mills AA. Throwing the cancer switch: reciprocal roles of polycomb and trithorax proteins. Nature reviews Cancer 2010; 10:669-82.

6. Xu ZQ, Zhang L, Gao BS, Wan YG, Zhang XH, Chen B, et al. EZH2 promotes tumor progression by increasing VEGF expression in clear cell renal cell carcinoma. Clinical \& translational oncology : official publication of the Federation of Spanish Oncology Societies and of the National Cancer Institute of Mexico 2015; 17:41-9.

7. Kim KH, Kim L, Choi SJ, Han JY, Kim JM, Chu YC, et al. The clinicopathological significance of epithelial mesenchymal transition associated protein expression in head and neck squamous cell carcinoma. Korean journal of pathology 2014; 48:263-9.

8. Ahani N, Shirkoohi R, Rokouei M, Alipour Eskandani M, Nikravesh A. Overexpression of enhancer of zeste human homolog 2 (EZH2) gene in human cytomegalovirus positive glioblastoma multiforme tissues. Medical oncology 2014; 31:252. 
9. Chisholm KM, Wan Y, Li R, Montgomery KD, Chang HY, West RB. Detection of long non-coding RNA in archival tissue: correlation with polycomb protein expression in primary and metastatic breast carcinoma. PloS one 2012; 7:e47998.

10. Reijm EA, Timmermans AM, Look MP, Meijer-van Gelder ME, Stobbe CK, van Deurzen CH, et al. High protein expression of EZH2 is related to unfavorable outcome to tamoxifen in metastatic breast cancer. Annals of oncology : official journal of the European Society for Medical Oncology / ESMO 2014; 25:2185-90.

11. Benard A, Goossens-Beumer IJ, van Hoesel AQ, Horati H, Putter H, Zeestraten EC, et al. Prognostic value of polycomb proteins EZH2, BMI1 and SUZ12 and histone modification H3K27me3 in colorectal cancer. PloS one 2014; 9:e108265.

12. Lu J, Zhao FP, Peng Z, Zhang MW, Lin SX, Liang BJ, et al. EZH2 promotes angiogenesis through inhibition of miR-1/Endothelin-1 axis in nasopharyngeal carcinoma. Oncotarget 2014; 5:11319-32.

13. Tang B, Du J, Li Y, Tang F, Wang Z, He S. EZH2 elevates the proliferation of human cholangiocarcinoma cells through the downregulation of RUNX3. Medical oncology 2014; 31:271.

14. Yu H, Simons DL, Segall I, Carcamo-Cavazos V, Schwartz EJ, Yan N, et al. PRC2/EED-EZH2 complex is up-regulated in breast cancer lymph node metastasis compared to primary tumor and correlates with tumor proliferation in situ. PloS one 2012; 7:e51239.

15. Suva ML, Riggi N, Janiszewska M, Radovanovic I, Provero P, Stehle JC, et al. EZH2 is essential for glioblastoma cancer stem cell maintenance. Cancer research 2009; 69:9211-8.

16. Jia N, Li Q, Tao X, Wang J, Hua K, Feng W. Enhancer of zeste homolog 2 is involved in the proliferation of endometrial carcinoma. Oncology letters 2014; 8:2049-54.

17. Xu C, Hao K, Hu H, Sheng Z, Yan J, Wang Q, et al. Expression of the enhancer of zeste homolog 2 in biopsy specimen predicts chemoresistance and survival in advanced non-small cell lung cancer receiving first-line platinum-based chemotherapy. Lung cancer 2014; 86:268-73.

18. Tiwari N, Tiwari VK, Waldmeier L, Balwierz PJ, Arnold P, Pachkov M, et al. Sox4 is a master regulator of epithelial-mesenchymal transition by controlling Ezh2 expression and epigenetic reprogramming. Cancer cell $2013 ; 23: 768-83$.

19. Liu X, Wang C, Chen Z, Jin Y, Wang Y, Kolokythas A, et al. MicroRNA-138 suppresses epithelial-mesenchymal transition in squamous cell carcinoma cell lines. The Biochemical journal 2011; 440:23-31.

20. Nolan KD, Franco OE, Hance MW, Hayward SW, Isaacs JS. Tumor-secreted Hsp90 subverts polycomb function to drive prostate tumor growth and invasion. The Journal of biological chemistry 2015; 290:8271-82.

21. Tong ZT, Cai MY, Wang XG, Kong LL, Mai SJ, Liu YH, et al. EZH2 supports nasopharyngeal carcinoma cell aggressiveness by forming a co-repressor complex with HDAC1/HDAC2 and Snail to inhibit E-cadherin. Oncogene 2012; 31:583-94.

22. Chen J, Xu H, Zou X, Wang J, Zhu Y, Chen H, et al. Snail recruits Ring1B to mediate transcriptional repression and cell migration in pancreatic cancer cells. Cancer research 2014; 74:4353-63.

23. Fujii S, Tokita K, Wada N, Ito K, Yamauchi C, Ito Y, et al. MEK-ERK pathway regulates EZH2 overexpression in association with aggressive breast cancer subtypes. Oncogene 2011; 30:4118-28.

24. Fujii S, Ito K, Ito Y, Ochiai A. Enhancer of zeste homologue 2 (EZH2) down-regulates RUNX3 by increasing histone H3 methylation. The Journal of biological chemistry 2008; 283:17324-32.

25. Fujii S, Ochiai A. Enhancer of zeste homolog 2 downregulates E-cadherin by mediating histone H3 methylation in gastric cancer cells. Cancer science 2008; 99:738-46. 
26. Foster CS, Falconer A, Dodson AR, Norman AR, Dennis N, Fletcher A, et al. Transcription factor E2F3 overexpressed in prostate cancer independently predicts clinical outcome. Oncogene 2004; 23:5871-9.

27. Tsai MC, Manor O, Wan Y, Mosammaparast N, Wang JK, Lan F, et al. Long noncoding RNA as modular scaffold of histone modification complexes. Science 2010; 329:689-93.

28. Santos M, Martinez-Fernandez M, Duenas M, Garcia-Escudero R, Alfaya B, Villacampa F, et al. In vivo disruption of an Rb-E2F-Ezh2 signaling loop causes bladder cancer. Cancer research 2014; 74:6565-77.

29. Hwang-Verslues WW, Chang PH, Jeng YM, Kuo WH, Chiang PH, Chang YC, et al. Loss of corepressor PER2 under hypoxia up-regulates OCT1-mediated EMT gene expression and enhances tumor malignancy. Proceedings of the National Academy of Sciences of the United States of America 2013; 110:12331-6.

30. Ferraro A, Mourtzoukou D, Kosmidou V, Avlonitis S, Kontogeorgos G, Zografos G, et al. EZH2 is regulated by ERK/AKT and targets integrin alpha2 gene to control Epithelial-Mesenchymal Transition and anoikis in colon cancer cells. The international journal of biochemistry \& cell biology 2013; 45:243-54.

31. Fiskus W, Wang Y, Sreekumar A, Buckley KM, Shi H, Jillella A, et al. Combined epigenetic therapy with the histone methyltransferase EZH2 inhibitor 3-deazaneplanocin A and the histone deacetylase inhibitor panobinostat against human AML cells. Blood 2009; 114:2733-43.

32. Zhang Y, Tong T. FOXA1 antagonizes EZH2-mediated CDKN2A repression in carcinogenesis. Biochemical and biophysical research communications 2014; 453:172-8.

33. Cui B, Yang Q, Guan H, Shi B, Hou P, Ji M. PRIMA-1, a mutant p53 reactivator, restores the sensitivity of TP53 mutant-type thyroid cancer cells to the histone methylation inhibitor 3-Deazaneplanocin A. The Journal of clinical endocrinology and metabolism 2014; 99:E962-70.

34. Fu HL, Ma Y, Lu LG, Hou P, Li BJ, Jin WL, et al. TET1 exerts its tumor suppressor function by interacting with p53-EZH2 pathway in gastric cancer. Journal of biomedical nanotechnology 2014; 10:1217-30.

35. Bai J, Ma M, Cai M, Xu F, Chen J, Wang G, et al. Inhibition enhancer of zeste homologue 2 promotes senescence and apoptosis induced by doxorubicin in p53 mutant gastric cancer cells. Cell proliferation 2014; 47:211-8.

36. Wu Z, Lee ST, Qiao Y, Li Z, Lee PL, Lee YJ, et al. Polycomb protein EZH2 regulates cancer cell fate decision in response to DNA damage. Cell death and differentiation 2011; 18:1771-9.

37. Wee ZN, Li Z, Lee PL, Lee ST, Lim YP, Yu Q. EZH2-mediated inactivation of IFN-gamma-JAK-STAT1 signaling is an effective therapeutic target in MYC-driven prostate cancer. Cell reports 2014; 8:204-16.

38. Qiu S, Huang D, Yin D, Li F, Li X, Kung HF, et al. Suppression of tumorigenicity by microRNA-138 through inhibition of EZH2-CDK4/6-pRb-E2F1 signal loop in glioblastoma multiforme. Biochimica et biophysica acta 2013; 1832:1697-707.

39. Coe BP, Thu KL, Aviel-Ronen S, Vucic EA, Gazdar AF, Lam S, et al. Genomic deregulation of the E2F/Rb pathway leads to activation of the oncogene EZH2 in small cell lung cancer. PloS one 2013; 8:e71670.

40. Tang X, Milyavsky M, Shats I, Erez N, Goldfinger N, Rotter V. Activated p53 suppresses the histone methyltransferase EZH2 gene. Oncogene 2004; 23:5759-69.

41. Bai J, Chen J, Ma M, Cai M, Xu F, Wang G, et al. Inhibiting enhancer of zeste homolog 2 promotes cellular senescence in gastric cancer cells SGC-7901 by activation of p21 and p16. DNA and cell biology 2014; 33:337-44.

42. Bracken AP, Pasini D, Capra M, Prosperini E, Colli E, Helin K. EZH2 is downstream of the pRB-E2F pathway, essential for proliferation and amplified in cancer. The EMBO journal 2003; 22:5323-35.

43. Iannetti A, Ledoux AC, Tudhope SJ, Sellier H, Zhao B, Mowla S, et al. Regulation of p53 and Rb links the 
alternative NF-kappaB pathway to EZH2 expression and cell senescence. PLoS genetics 2014; 10:e1004642. 44. Wu ZL, Zheng SS, Li ZM, Qiao YY, Aau MY, Yu Q. Polycomb protein EZH2 regulates E2F1-dependent apoptosis through epigenetically modulating Bim expression. Cell death and differentiation 2010; 17:801-10.

45. Mu Z, Li H, Fernandez SV, Alpaugh KR, Zhang R, Cristofanilli M. EZH2 knockdown suppresses the growth and invasion of human inflammatory breast cancer cells. Journal of experimental \& clinical cancer research : CR $2013 ; 32: 70$.

46. Sun J, Zheng G, Gu Z, Guo Z. MiR-137 inhibits proliferation and angiogenesis of human glioblastoma cells by targeting EZH2. Journal of neuro-oncology 2015; 122:481-9.

47. Yoo KH, Hennighausen L. EZH2 methyltransferase and H3K27 methylation in breast cancer. International journal of biological sciences 2012; 8:59-65.

48. Mitic T, Caporali A, Floris I, Meloni M, Marchetti M, Urrutia R, et al. EZH2 modulates angiogenesis in vitro and in a mouse model of limb ischemia. Molecular therapy : the journal of the American Society of Gene Therapy $2015 ; 23: 32-42$.

49. Simon C, Chagraoui J, Krosl J, Gendron P, Wilhelm B, Lemieux S, et al. A key role for EZH2 and associated genes in mouse and human adult T-cell acute leukemia. Genes \& development 2012; 26:651-6.

50. Mallen-St Clair J, Soydaner-Azeloglu R, Lee KE, Taylor L, Livanos A, Pylayeva-Gupta Y, et al. EZH2 couples pancreatic regeneration to neoplastic progression. Genes \& development 2012; 26:439-44.

51. Kim E, Kim M, Woo DH, Shin Y, Shin J, Chang N, et al. Phosphorylation of EZH2 activates STAT3 signaling via STAT3 methylation and promotes tumorigenicity of glioblastoma stem-like cells. Cancer cell 2013; 23:839-52.

52. Fouse SD, Costello JF. Cancer Stem Cells Activate STAT3 the EZ Way. Cancer cell 2013; 23:711-3.

53. Xu K, Wu ZJ, Groner AC, He HH, Cai C, Lis RT, et al. EZH2 oncogenic activity in castration-resistant prostate cancer cells is Polycomb-independent. Science 2012; 338:1465-9.

54. Yan J, Ng SB, Tay JL, Lin B, Koh TL, Tan J, et al. EZH2 overexpression in natural killer/T-cell lymphoma confers growth advantage independently of histone methyltransferase activity. Blood 2013; 121:4512-20.

55. Gonzalez ME, Moore HM, Li X, Toy KA, Huang W, Sabel MS, et al. EZH2 expands breast stem cells through activation of NOTCH1 signaling. Proceedings of the National Academy of Sciences of the United States of America 2014; 111:3098-103.

56. Jung HY, Jun S, Lee M, Kim HC, Wang X, Ji H, et al. PAF and EZH2 induce Wnt/beta-catenin signaling hyperactivation. Molecular cell 2013; 52:193-205.

57. Lee ST, Li Z, Wu Z, Aau M, Guan P, Karuturi RK, et al. Context-specific regulation of NF-kappaB target gene expression by EZH2 in breast cancers. Molecular cell 2011; 43:798-810.

58. Lei Q, Shen F, Wu J, Zhang W, Wang J, Zhang L. MiR-101, downregulated in retinoblastoma, functions as a tumor suppressor in human retinoblastoma cells by targeting EZH2. Oncology reports 2014; 32:261-9.

59. Sander S, Bullinger L, Klapproth K, Fiedler K, Kestler HA, Barth TF, et al. MYC stimulates EZH2 expression by repression of its negative regulator miR-26a. Blood 2008; 112:4202-12.

60. Varambally S, Cao Q, Mani RS, Shankar S, Wang X, Ateeq B, et al. Genomic loss of microRNA-101 leads to overexpression of histone methyltransferase EZH2 in cancer. Science 2008; 322:1695-9.

61. Liu T, Hou L, Huang Y. EZH2-specific microRNA-98 inhibits human ovarian cancer stem cell proliferation via regulating the pRb-E2F pathway. Tumour biology : the journal of the International Society for Oncodevelopmental Biology and Medicine 2014; 35:7239-47.

62. Guo Y, Ying L, Tian Y, Yang P, Zhu Y, Wang Z, et al. miR-144 downregulation increases bladder cancer cell 
proliferation by targeting EZH2 and regulating Wnt signaling. The FEBS journal 2013; 280:4531-8.

63. Karoopongse E, Yeung C, Byon J, Ramakrishnan A, Holman ZJ, Jiang PY, et al. The KDM2B- let-7b -EZH2 axis in myelodysplastic syndromes as a target for combined epigenetic therapy. PloS one 2014; 9:e107817.

64. Liu L, Guo J, Yu L, Cai J, Gui T, Tang H, et al. miR-101 regulates expression of EZH2 and contributes to progression of and cisplatin resistance in epithelial ovarian cancer. Tumour biology : the journal of the International Society for Oncodevelopmental Biology and Medicine 2014; 35:12619-26.

65. Zhang D, Ni Z, Xu X, Xiao J. MiR-32 functions as a tumor suppressor and directly targets EZH2 in human oral squamous cell carcinoma. Medical science monitor : international medical journal of experimental and clinical research 2014; 20:2527-35.

66. Lin L, Zheng Y, Tu Y, Wang Z, Liu H, Lu X, et al. MicroRNA-144 suppresses tumorigenesis and tumor progression of astrocytoma by targeting EZH2. Human pathology 2015; 46:971-80.

67. Liu F, He Y, Shu R, Wang S. MicroRNA-1297 regulates hepatocellular carcinoma cell proliferation and apoptosis by targeting EZH2. International journal of clinical and experimental pathology 2015; 8:4972-80.

68. Hibino S, Saito Y, Muramatsu T, Otani A, Kasai Y, Kimura M, et al. Inhibitors of enhancer of zeste homolog 2 (EZH2) activate tumor-suppressor microRNAs in human cancer cells. Oncogenesis 2014; 3:e104.

69. Huang D, Qiu S, Ge R, He L, Li M, Li Y, et al. miR-340 suppresses glioblastoma multiforme. Oncotarget 2015; 6:9257-70.

70. Zhao X, Lwin T, Zhang X, Huang A, Wang J, Marquez VE, et al. Disruption of the MYC-miRNA-EZH2 loop to suppress aggressive B-cell lymphoma survival and clonogenicity. Leukemia 2013; 27:2341-50.

71. Tao T, Liu D, Liu C, Xu B, Chen S, Yin Y, et al. Autoregulatory feedback loop of EZH2/miR-200c/E2F3 as a driving force for prostate cancer development. Biochimica et biophysica acta 2014; 1839:858-65.

72. Koumangoye RB, Andl T, Taubenslag KJ, Zilberman ST, Taylor CJ, Loomans HA, et al. SOX4 interacts with EZH2 and HDAC3 to suppress microRNA-31 in invasive esophageal cancer cells. Molecular cancer 2015; 14:24.

73. Cha TL, Zhou BP, Xia W, Wu Y, Yang CC, Chen CT, et al. Akt-mediated phosphorylation of EZH2 suppresses methylation of lysine 27 in histone H3. Science 2005; 310:306-10.

74. Chen B, Liu J, Chang Q, Beezhold K, Lu Y, Chen F. JNK and STAT3 signaling pathways converge on Akt-mediated phosphorylation of EZH2 in bronchial epithelial cells induced by arsenic. Cell cycle 2013; 12:112-21.

75. Li L, Qiu P, Chen B, Lu Y, Wu K, Thakur C, et al. Reactive oxygen species contribute to arsenic-induced EZH2 phosphorylation in human bronchial epithelial cells and lung cancer cells. Toxicology and applied pharmacology 2014; 276:165-70.

76. Lin YW, Ren LL, Xiong H, Du W, Yu YN, Sun TT, et al. Role of STAT3 and vitamin D receptor in EZH2-mediated invasion of human colorectal cancer. The Journal of pathology 2013; 230:277-90.

77. Feng H, Yu Z, Tian Y, Lee YY, Li MS, Go MY, et al. A CCRK-EZH2 epigenetic circuitry drives hepatocarcinogenesis and associates with tumor recurrence and poor survival of patients. Journal of hepatology 2015; 62:1100-11.

78. Wu SC, Zhang Y. Cyclin-dependent kinase 1 (CDK1)-mediated phosphorylation of enhancer of zeste 2 (Ezh2) regulates its stability. The Journal of biological chemistry 2011; 286:28511-9.

79. Kaneko S, Li G, Son J, Xu CF, Margueron R, Neubert TA, et al. Phosphorylation of the PRC2 component Ezh2 is cell cycle-regulated and up-regulates its binding to ncRNA. Genes \& development 2010; 24:2615-20.

80. Van Hoof D, Munoz J, Braam SR, Pinkse MW, Linding R, Heck AJ, et al. Phosphorylation dynamics during 
early differentiation of human embryonic stem cells. Cell stem cell 2009; 5:214-26.

81. Wei Y, Chen YH, Li LY, Lang J, Yeh SP, Shi B, et al. CDK1-dependent phosphorylation of EZH2 suppresses methylation of H3K27 and promotes osteogenic differentiation of human mesenchymal stem cells. Nature cell biology 2011; 13:87-94.

82. Chen S, Bohrer LR, Rai AN, Pan Y, Gan L, Zhou X, et al. Cyclin-dependent kinases regulate epigenetic gene silencing through phosphorylation of EZH2. Nature cell biology 2010; 12:1108-14.

83. Yang CC, LaBaff A, Wei Y, Nie L, Xia W, Huo L, et al. Phosphorylation of EZH2 at T416 by CDK2 contributes to the malignancy of triple negative breast cancers. American journal of translational research 2015; 7:1009-20.

84. Liu TP, Lo HL, Wei LS, Hsiao HH, Yang PM. S-Adenosyl-L-methionine-competitive inhibitors of the histone methyltransferase EZH2 induce autophagy and enhance drug sensitivity in cancer cells. Anti-cancer drugs 2015; 26:139-47.

85. Girard N, Bazille C, Lhuissier E, Benateau H, Llombart-Bosch A, Boumediene K, et al. 3-Deazaneplanocin A (DZNep), an inhibitor of the histone methyltransferase EZH2, induces apoptosis and reduces cell migration in chondrosarcoma cells. PloS one 2014; 9:e98176.

86. Tan J, Yang X, Zhuang L, Jiang X, Chen W, Lee PL, et al. Pharmacologic disruption of Polycomb-repressive complex 2-mediated gene repression selectively induces apoptosis in cancer cells. Genes \& development 2007; 21:1050-63.

87. Hayden A, Johnson PW, Packham G, Crabb SJ. S-adenosylhomocysteine hydrolase inhibition by 3-deazaneplanocin A analogues induces anti-cancer effects in breast cancer cell lines and synergy with both histone deacetylase and HER2 inhibition. Breast cancer research and treatment 2011; 127:109-19.

88. Kikuchi J, Takashina T, Kinoshita I, Kikuchi E, Shimizu Y, Sakakibara-Konishi J, et al. Epigenetic therapy with 3-deazaneplanocin A, an inhibitor of the histone methyltransferase EZH2, inhibits growth of non-small cell lung cancer cells. Lung cancer 2012; 78:138-43.

89. Lee JK, Kim KC. DZNep, inhibitor of S-adenosylhomocysteine hydrolase, down-regulates expression of SETDB1 H3K9me3 HMTase in human lung cancer cells. Biochemical and biophysical research communications 2013; 438:647-52.

90. Ueda K, Yoshimi A, Kagoya Y, Nishikawa S, Marquez VE, Nakagawa M, et al. Inhibition of histone methyltransferase EZH2 depletes leukemia stem cell of mixed lineage leukemia fusion leukemia through upregulation of p16. Cancer science 2014; 105:512-9.

91. Simon JA, Lange CA. Roles of the EZH2 histone methyltransferase in cancer epigenetics. Mutation research 2008; 647:21-9.

92. Verma SK, Tian X, LaFrance LV, Duquenne C, Suarez DP, Newlander KA, et al. Identification of Potent, Selective, Cell-Active Inhibitors of the Histone Lysine Methyltransferase EZH2. ACS medicinal chemistry letters 2012; 3:1091-6.

93. Qi W, Chan H, Teng L, Li L, Chuai S, Zhang R, et al. Selective inhibition of Ezh2 by a small molecule inhibitor blocks tumor cells proliferation. Proceedings of the National Academy of Sciences of the United States of America 2012; 109:21360-5.

Abbreviation:

Tumor-suppressive genes (TCG)

Glioblastoma multiforme (GBMs)

Cancer Stem Cell (CSC) 
castration-resistant prostate cancer (CRPC)

androgen receptor (AR)

PCNA-associated factor (PAF)

triple-negative breast cancer (TNBC)

colon cancer (CC)

natural killer/T-cell lymphoma (NKTL)

vitamin D receptor (VDR)

ovarian cancer stem cells (OCSCs)

androgen receptor (AR)

squamous cell lung cancer (SCLC)

hepatocellular carcinoma (HCC)

$\mathrm{T}$-cell factor(TCF)

p53 wild-type (p53-wt)

nasopharyngeal carcinoma (NPC)

rhabdomyosarcoma (RMS)

mixed lineage leukemia (MLL)

Prostate cancer $(\mathrm{PCa})$

F-box protein 32 (FBXO32)

cell cycle-related kinase (CCRK) 


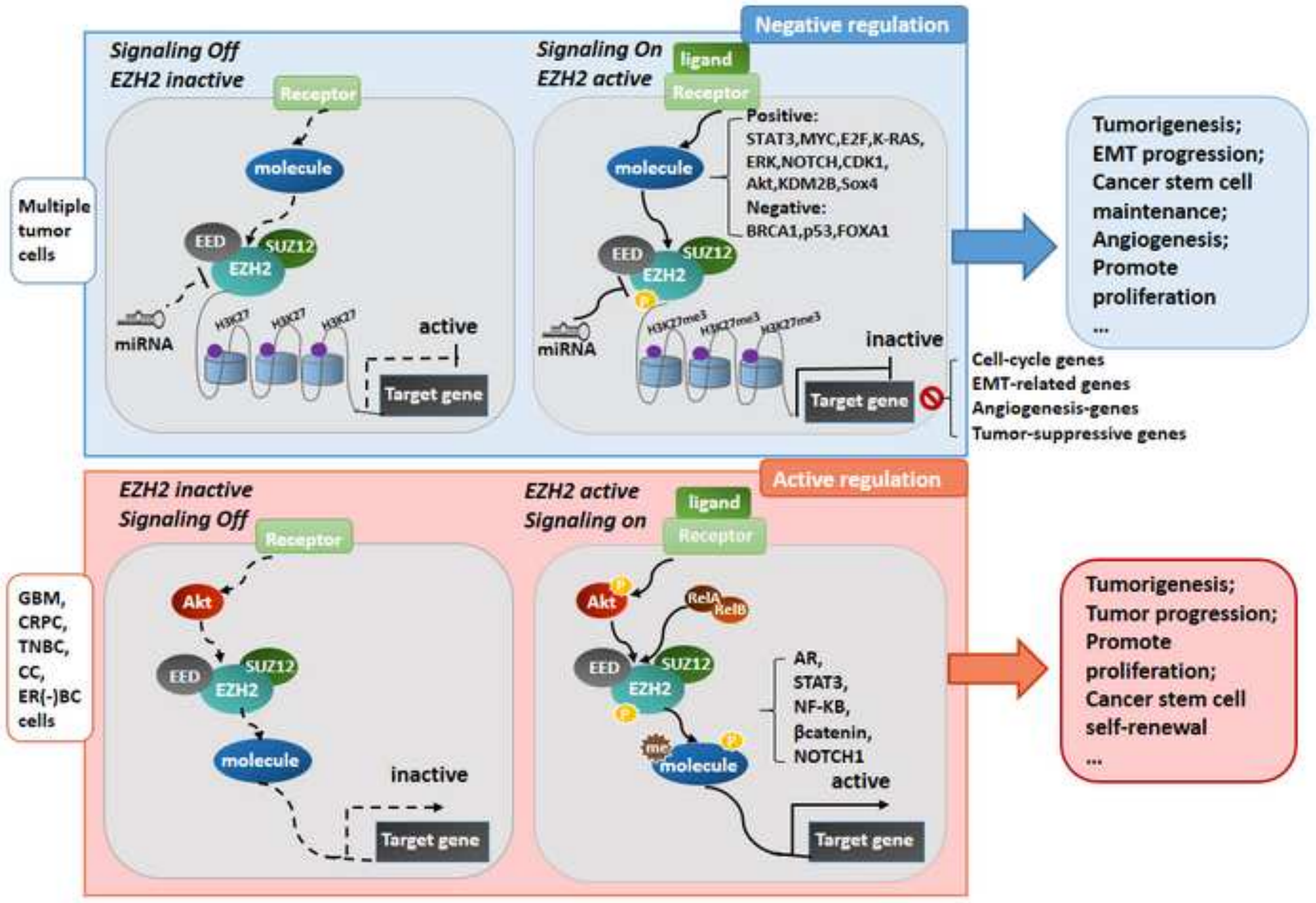




\section{Silencing Confrontation: EZH2 versus MicroRNAs in Tumors}

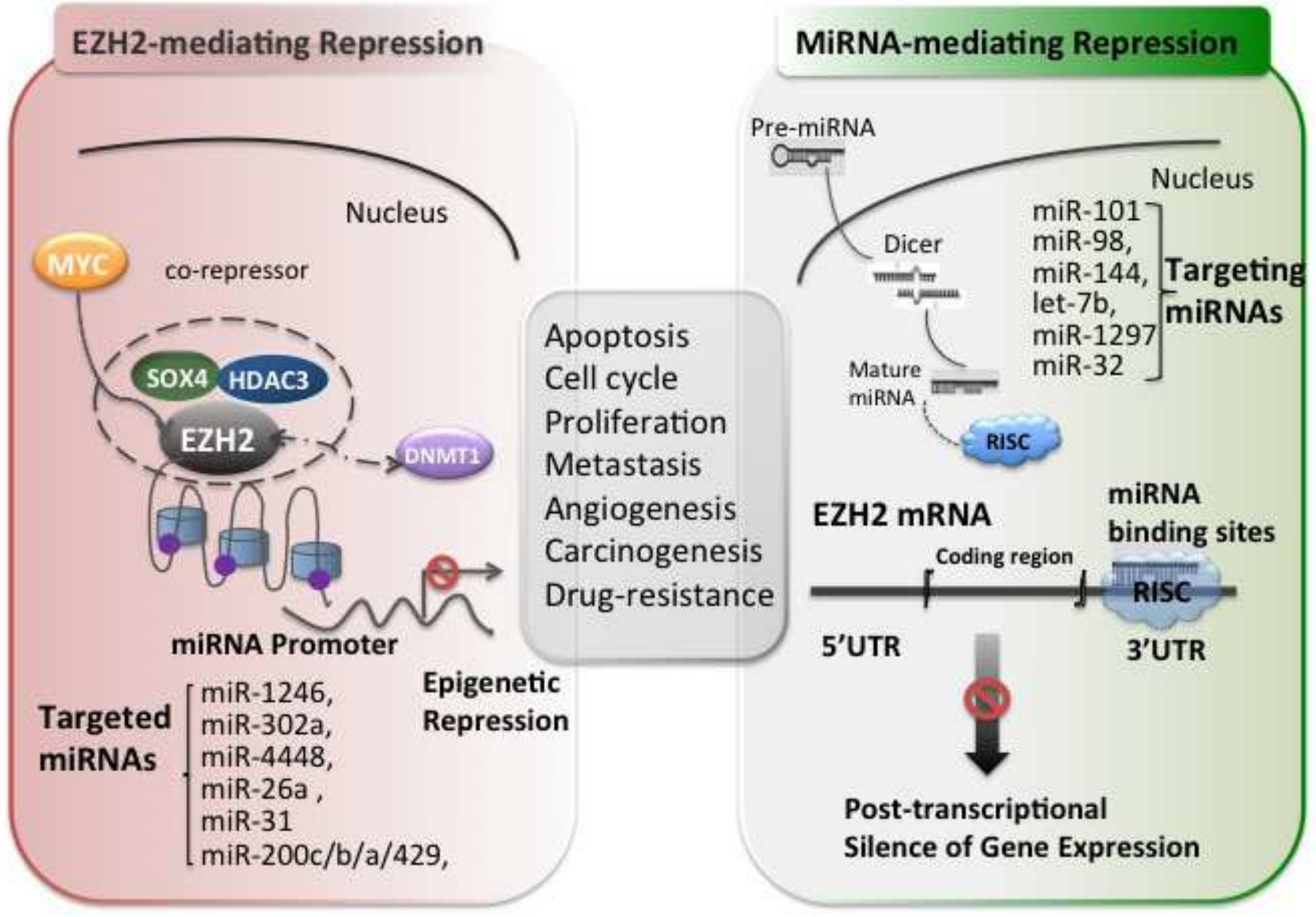


Table1. The Upstream Signal Modulators of EZH2 and PcG-mediating Silence in Tumors

\begin{tabular}{|c|c|c|c|c|c|}
\hline Modulator & Organism/system & Mechanisms & Polycomb Target Loci & Effects & Ref. \\
\hline BRCA1 & $\begin{array}{l}\text { Mouse ES cells; } \\
\text { Breast Cancer }\end{array}$ & $\begin{array}{l}\text { BRCA1-binding region in EZH2 overlaps with HOTAIR-binding } \\
\text { region }\end{array}$ & TCG & $\begin{array}{l}\text { ES Cell Differentiation; } \\
\text { Carcinogenesis }\end{array}$ & $\begin{array}{l}{[101]} \\
{[100]}\end{array}$ \\
\hline P53 & $\begin{array}{l}\text { Normal Fibroblast; } \\
\text { Gastric Cancer; } \\
\text { Thyroid Cancer }\end{array}$ & $\begin{array}{l}\text { EZH2 modulates p53-wt cells by p21; } \\
\text { EZH2 affects p53-deficient cell via Chk1 }\end{array}$ & $\begin{array}{l}\text { FBXO32, Chk1 } \\
\text { p21 }\end{array}$ & $\begin{array}{l}\text { Proliferation; } \\
\text { Antagonize Senescence; } \\
\text { Regulate Cell Cycle }\end{array}$ & $\begin{array}{l}{[106]} \\
{[2]} \\
{[15]}\end{array}$ \\
\hline $\begin{array}{l}\text { JAK/STAT } \\
3\end{array}$ & $\begin{array}{l}\text { Bronchus } \\
\text { Epithelium; } \\
\text { Colorectal Cancer }\end{array}$ & $\begin{array}{l}\text { Activated pEZH2-Ser-21 causes PRC2 dissociation from } \\
\text { chromatin to weaken } \mathrm{H} 3 \mathrm{~K} 27 \mathrm{me} 3 \text { in nuclei. }\end{array}$ & VDR & $\begin{array}{l}\text { Proliferation; } \\
\text { Metastasis }\end{array}$ & {$[51]$} \\
\hline $\mathbf{E} 2 \mathbf{F} / \mathbf{R b}$ & $\begin{array}{l}\text { SCLC; } \\
\text { OCSC; } \\
\text { Bladder Cancer; } \\
\text { PCa; } \\
\text { GBM; } \\
\text { HCC }\end{array}$ & $\begin{array}{l}\text { Hyperactivated EZH2 recurrents DNA level E2F/Rb disruption; } \\
\text { E2Fs transactivate and bind to PRC2 promoters; } \\
\text { Autoregulatory Feedback Loop (EZH2/miR-200c/E2F3); } \\
\text { EZH2-CDK4/6-pRb-E2F1 Signal Loop } \\
\text { Positive Epigenetic } \\
\text { Circuitry---CCRK/GSK-3 } \beta / \beta \text {-catenin/TCF/E2F1/EZH2 }\end{array}$ & $\begin{array}{l}\text { p21 } \\
\text { CDK2 } 2 \text {; cDKclinE, c-myc; } \\
\text { Bim }\end{array}$ & $\begin{array}{l}\text { Proliferation; } \\
\text { Carcinogenesis ; } \\
\text { Repress Apoptosis; }\end{array}$ & $\begin{array}{l}{[14]} \\
{[56]} \\
{[88]} \\
{[72]} \\
{[17]}\end{array}$ \\
\hline MEK/ERK & $\begin{array}{l}\text { Breast Cancer; PCa; } \\
\text { Colon Cancer }\end{array}$ & $\begin{array}{l}\text { Enrichment of EZH2 and H3K27me3 on Target Promoters; } \\
\text { EZH2 promoter occupancy by (JUN/FOS) AP-1components }\end{array}$ & $\begin{array}{l}\text { E-cadherin, Runx3; Elk; } \\
\text { ITG } \alpha 2\end{array}$ & $\begin{array}{l}\text { Aggressiveness; } \\
\text { Inhibit Anoikis }\end{array}$ & $\begin{array}{l}{[23]} \\
{[18]}\end{array}$ \\
\hline \multicolumn{6}{|l|}{ FOX } \\
\hline $\begin{array}{l}\text { Family } \\
\text { FOXA1 }\end{array}$ & $\begin{array}{l}\mathrm{PCa} \\
\text { Breast Cancer; }\end{array}$ & $\begin{array}{l}\text { FOXA1 inhibits EZH2 via its C-terminal histone binding motif; } \\
\text { MELK-FOXM1-EZH2 axis; }\end{array}$ & $\begin{array}{l}\mathrm{p} 16^{\mathrm{INK} 4 \mathrm{a}} \\
-\end{array}$ & $\begin{array}{l}\text { Carcinogenesis; } \\
\text { Irradiation Resistance; }\end{array}$ & $\begin{array}{l}{[117]} \\
{[46]}\end{array}$ \\
\hline FOXM1 & GSC; & Enrichment of EZH 2 and $\mathrm{H} 3 \mathrm{~K} 27 \mathrm{me} 3$ on $\mathrm{FBXO} 32$ Promoter; & FBXO32 & Repress Apoptosis & {$[13]$} \\
\hline $\begin{array}{l}\text { FOXO1 } \\
\text { FOXP3 }\end{array}$ & $\begin{array}{l}\text { RMS; } \\
\text { Breast Cancer }\end{array}$ & $\begin{array}{l}\text { FOXP3 accelerates EZH2 Degradation by } \\
\text { polyubiquitination-proteasome pathway; }\end{array}$ & Praja1 & $\begin{array}{l}\text { Mammosphere } \\
\text { Formation, }\end{array}$ & {$[80]$} \\
\hline & & Histone acetylation and $\mathrm{H} 3 \mathrm{~K} 27 \mathrm{me} 3$ at $\mathrm{FOXC} 1$ promoter & FOXC1 & Proliferation, & {$[16]$} \\
\hline-- & & & & $\begin{array}{l}\text { Migration; } \\
\text { Clonogenicity }\end{array}$ & \\
\hline
\end{tabular}


Table 2 Targets Activated by EZH2 in an Epigenetic-independent Manner

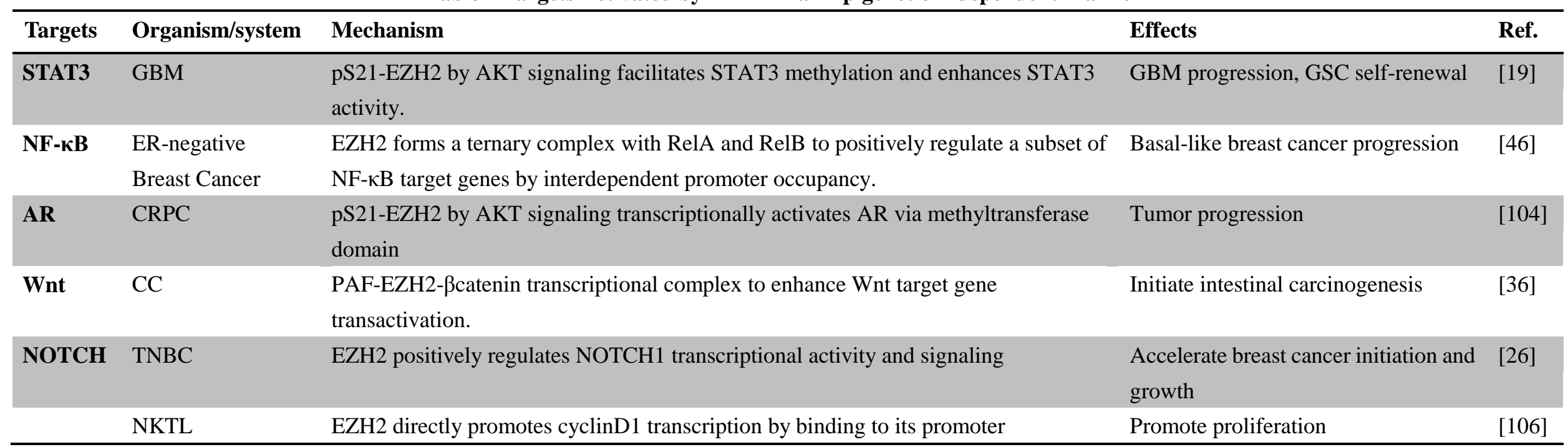

